\title{
THE HUMAN AND ANIMAL LIVER AFTER ALCOHOL*
}

\author{
FRANK A. MCJUNKIN, M.D. \\ MILWAUKEE, WIS.
}

\section{INTRODUCTION}

Long before the microscope came to play the important rôle in pathology that it now does, the liver, in common with other large organs, presented changes for gross study. Thus Laennec ${ }^{1}$ in his work on auscultation, published in 1829 , mentions in a case of ascites the presence of a small liver with coarsely granular surface. Owing to the yellowish color of the organ he applied the term cirrhose.

The term cirrhosis has survived, and, like other terms that are not applied to given conditions of definite etiology, it has not always been ased in the same way. We do not hesitate to call the condition in which there is a complete loss of liver lobules with the formation of wide bands of connective tissue, a cirrhosis, but if there is a moderate increase of connective tissue about the portal areas and along the interlobular lines, the term sclerosis is likely to be preferred. Many authors, however, speak of the moderate increase of connective tissue that may follow, for instance, a tuberculous process in the liver, as a cirrhosis. At present, perhaps, the commonest usage is to apply cirrhosis to the more extensive grades of sclerotic change in the liver.

Following the observation of Laennec, a large mass of literature accumulated dealing with the etiologic factors that produce or appear to produce liver cirrhoses. For the most part it is difficult to place the credit for our present knowledge of the causative agents. MacCallum ${ }^{2}$ and $\mathrm{Kretz}^{3}$ have pointed out the way in which regeneration of the cells gives rise to large islands of liver cells with complete loss of lobulation; Levaditi and others are responsible for our ability to demonstrate the relationship between the Treponema pallidum in the liver and the sclerotic changes present; while Mallory ${ }^{4}$ has shown that a characteristic hyaline (Fig. 1) change is present in the cytoplasm of the liver cells of cirrhosis of a certain type.

* Submitted for publication Nov. 6, 1916.

* From the Pathological Laboratory, Boston City Hospital. and the Pathological Department, Marquette University School of Medicine.

2. MacCallum, W. G.: Regenerative Changes in Cirrhosis of the Liver,

1. Laennec, R. T. H.: De L' Ausculation Mediate, 1819, 1, 368. Jour. Am. Med. Assn., 1904, 43, 649.

3. Kretz, R.: Ueber Lebercirrhose, Wien. klin. Wchnschr., 1900, 12, 271.

4. Mallory, F. B.: Bull. Johns Hopkins Hosp., 1911, 22, 69. 
The etiology of those cirrhoses, in which the causative agent is present in the tissue as a morphologic element, was the first to be established, and there is at present, therefore, much greater certainty in regard to the mechanical (carbon and hemosiderin deposits), infectious (colon and possibly other ascending gall-duct infections) and syphilitic varieties than there is concerning the toxic. Leaving out of account the central scleroses produced by certain bacterial toxins and which may be induced by chloroform, the etiology of toxic liver lesions is yet obscure. This applies to the sclerosis following acute yellow atrophy.

Owing to the frequent history of alcoholism, ethyl alcohol was looked on as an active factor in the production of liver cirrhosis shortly after the observations of Laennec. Later, cirrhotic livers were found in infants and youths that had never used alcohol. This confused matters until the mechanical, syphilitic, and infectious varieties were clearly defined. Now, as during the earlier observations, a feature of these cases of unknown etiology is the excessive use of alcohol, especially of distilled liquors.

\section{HUMAN CIRRHOSIS OF UNKNOWN ETIOLOGY}

In a series of thirty recent cases of cirrhosis of unknown etiology coming to necropsy from the wards of the Boston City Hospital, the clinical records of twenty-eight make note of alcoholism. On the other hand, the majority of those dying from chronic alcoholism in the alcoholic wards of the hospitals show no abnormal changes in the liver. The excessive use of alcohol does not, therefore, always produce liver lesions in the human, while some workers along this line are willing to say that it never does. Many say that it does so indirectly by causing lesions in the gastro-intestinal tract, with a resulting autointoxication, while others say that alcoholic cirrhosis results from some impurity in the liquors. The most that can be said from the clinical study of human cases is that the majority of those with a cirrhosis not infectious or syphilitic (and not mechanical) use or have used alcohol to excess.

These cases were chosen from necropsies performed at the Boston City Hospital by examining the sections of liver for hyalin-containing cells. This examination excluded cases of sclerosis resulting from an attack of so-called acute yellow atrophy, in which the hyaline degeneration is not present and the lesion is not active and progressive. The microscopic examination makes possible the elimination of mechanical lesions from carbon or other pigment deposits and lesions from the extension of an infectious process up the bile passages, while the microscopic and gross appearance, together with the clinical history and clinical laboratory tests enable one to be quite sure that no cases of syphilis are included. These cases, then, are instances of cirrhosis 
of unknown etiology, most of which are more or less alcoinolic. The chief interest in the series is that the similarity in the microscopic appearance points to one toxic agent or to toxic substances acting in practically the same way. Thirty cases were taken; of these, Cases 1 to 5 show very little sclerosis, 6 to 9 are in the transition stage, while 10 to 30 are late, with extensive sclerosis. Cases 1 to 10 show each step in the process that ends with the typical "hobnail" liver.

The hyaline network in the affected cells has been accurately described by Mallory. This change is fully as evident as the nuclei of the cells themselves (Fig. 1). It is not present in cirrhosis of known etiology and is lacking in the degenerating cells of other liver affections. An interesting feature of the histologic study of the early cases ( 1 to 9 ) is that although the lobules are irregularly involved, the process is more severe toward the central hepatic vein.

To summarize, the thirty cases of this series are not cirrhoses of mechanical, infectious or syphilitic origin in the sense that these terms are used in the foregoing. Although the liver lesion is of toxic origin, it differs from acute yellow atrophy.where the lesion is not progressive and where there is no hyaline degeneration of the liver cells, and from the central necrosis and sclerosis that may follow chloroform or bacterial toxins, where the lesion is not progressive and there are no hyaline-containing cells.

\section{REPORT OF CASES}

CASE 1.-M. F., woman, aged 28. The patient's sister says "patient has been drinking a good deal of late;" clinical diagnosis, alcoholic neuritis; patient died eleven days after admission to the hospital. .

Liver weighs $1,800 \mathrm{gm}$.; the surface is smooth; microscopically the normal lobulation is present; there is no necrosis and no sclerosis. A few lobules have a single cell with a typical hyaline network. The other cells are normal except for a slight edema of those near the central vein. In all of the following cases there has been a loss and a failure of regeneration of a sufficient number of cells to lead to areas of sclerosis in the lobules or to sclerosis of entire lobules.

CASE 2.-J. W., man, aged 33. During the last few weeks the patient has grown weaker and at his lodging house he was often helped to his room when intoxicated. He was admitted to the hospital in an unconscious condition and died on the day of admission.

Weight of the liver $1,730 \mathrm{gm}$; surface is smooth; microscopically, the lobulation is normal. There is a slight sclerosis which differs from the usual central toxic sclerosis (chloroform, streptococcus toxin, etc.) in that it is not confined to the zone about the central hepatic vein, but extends irregularly at one or more points toward the portal tissue and may even reach the periphery of the lobule.

On examining these areas of sclerosis with an oil immersion lens, a majority of the cells are found to have disappeared, not only from the inner ends of groups of trabeculae, but also from the intermediate and outer portions. Some of the liver cells remaining in these trabeculae are normal while others contain hyalin.

CASE 3.-F. W., man, aged 41. The patient came to the hospital with a history of recent hard drinking, developed delirium tremens and died on the seventeenth day after admission. 
Weight of the liver $1,975 \mathrm{gm}$; surface is smooth. Microscopically the liver is like that in Case 2 .

CASE 4.-W. G., man, aged 49, had been very alcoholic, and for two weeks had had facial erysipelas; entered the hospital delirious and died on the second day following admission.

Weight of the liver $2,680 \mathrm{gm}$; the surface is granular. Microscopically the liver is like the organs in Cases 2 and 3 , except that the loss of cells from trabeculae is very diffuse and the number of hyalin-containing cells in every part of the lobule is practically the same.

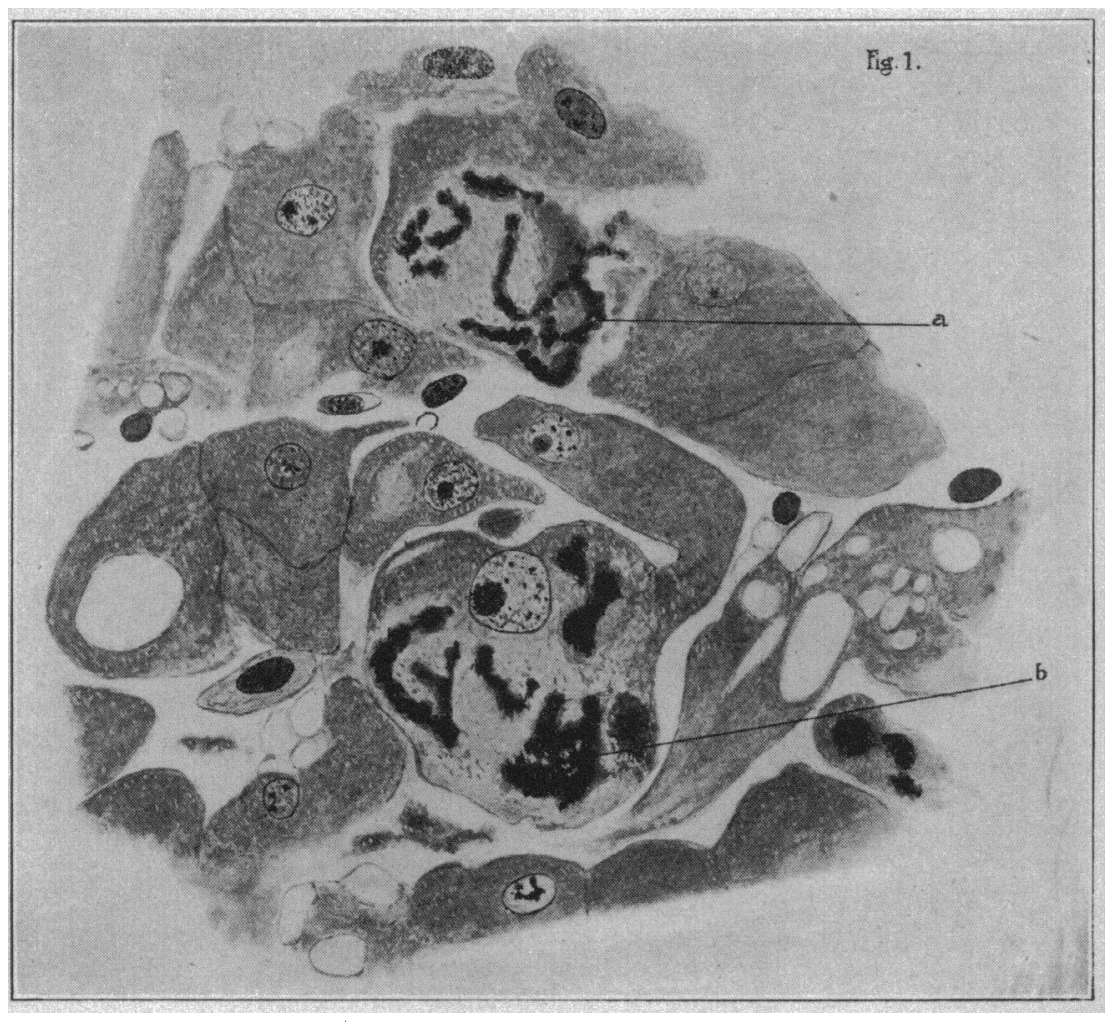

Fig. 1.-High power magnification of the liver from a case of human cirrhosis of unknown etiology (Case 7), $a$ and $b$ are two cells showing the hyaline degeneration of the cells that characterizes this variety of cirrhosis. $b$ shows nucleus intact which is the case in a considerable number of the cells so affected. Such cells are very often invaded by leukocytes, but neither of these cells has been so involved.

CASE 5.-G. T., man, aged 35, drank three to four glasses of whisky daily; died on the fifth day after admission.

Weight of the liver 2,560 $\mathrm{gm}$.; surface of the liver is smooth. Microscopically the liver is like the organs in Cases 2 and 3 .

CASE 6.-M. B., woman, aged 48, drank one pint of whisky per week; also beer. She was intoxicated when admitted to the hospital and died one month from date of admission. 
Weight of the liver $2.400 \mathrm{gm}$; surface smooth. Here the process is somewhat more extensive. The loss of cells from trabeculae reaches from central veins to portal areas and in many lobules the majority of the cells are gone. Most of the section is made up of sclerosed lobules with small islands of cells about the portal areas. In places an island of normal liver cells lies only on one side of a portal area.

CASE 7.-A. W., woman, aged 35, used some alcohol; in bed for one week with vomiting and diarrhea; no jaundice; died six days after admission to the hospital.

Weight of the liver $1,670 \mathrm{gm}$.; surface is granular. Microscopically the amount of sclerosis is the same as in Case 6.

CASE 8.-M. T., woman, aged 55, drank one pint of gin daily; had been a heavy drinker for three years; had jaundice for four weeks; died eighteen days after admission.

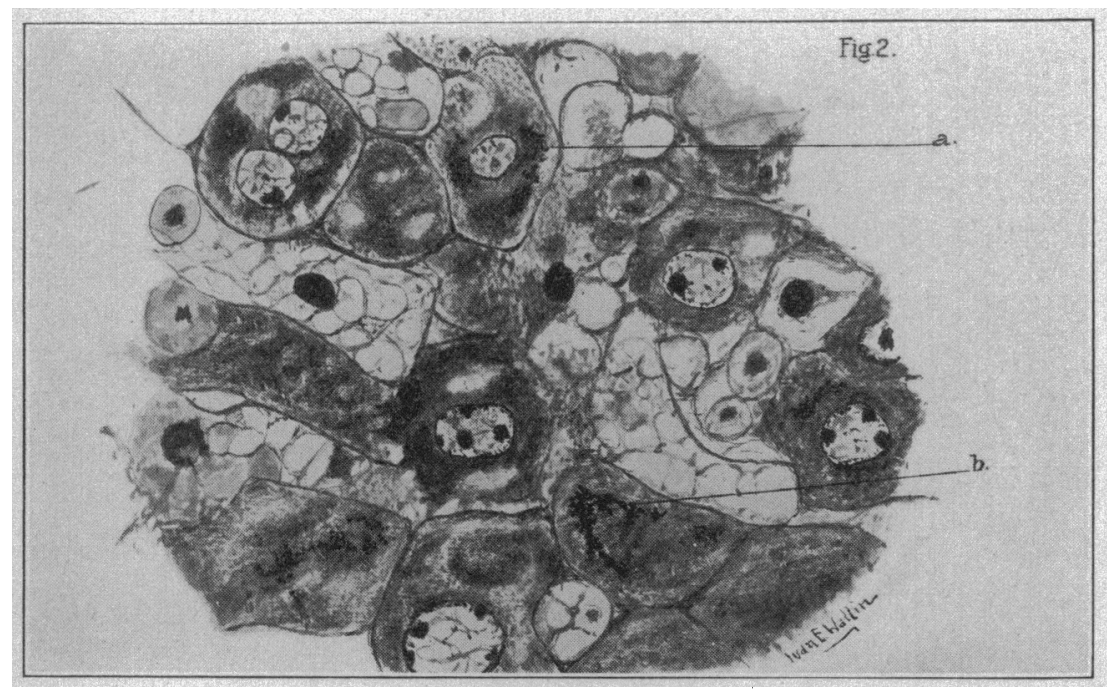

Fig. 2.-High power magnification of the liver from a rabbit that received $4 \mathrm{gm}$. lead acetate forty-eight hours before being killed. $a$ and $b$ are two cells that show a fine granulation in the form of a network. Many of these cells become invaded by leukocytes and undergo necrosis. This network gives a black precipitate when treated with an alkaline sulphid, a reaction that differentiates this change from that shown in Figure 1.

Weight of the liver $1.800 \mathrm{gm}$; surface is granular. Microscopically this liver is typically in the stage of transition from a sclerosis of lobules to a sclerosis with a loss of lobules and the formation of islands of liver cells. The tendency for these islands of unaffected cells to lie about the portal tissue is shown by the two preceding cases. In some lobules some irregular sclerosis about the central hepatic vein extends to the portal tissue, and in this way circular bands made up of one to several portal tracts are formed. These bands inclose islands of liver cells made up of the parts of one or more lobules next the portal tissue.

CASE 9.-L. B., man, aged 58, had never been sick; never used liquor to excess, but drank more during the previous month; jaundiced for one month; gradually weakened and died eighteen days after admission to the hospital. 
Weight of the liver $2,750 \mathrm{gm}$; surface is granular. Microscopically, sections show beautifully the inclosing of peripheral portions of lobules by bands made up of portal areas connected with the irregular central scleroses.

CASE 10.-B. T., man, aged 50, drank three to four whiskies and four to five beers per day; eight months previous to admission he felt tired in the morning and would take a glass of brandy to stop his vomiting; for two months the abdomen had been enlarging and he had had diarrhea; he was slightly jaundiced on admission and died eight days later.

Weight of the liver $1,220 \mathrm{gm}$; ; surface is granular. Microscopically this liver is made up of islands of liver cells of very irregular shape and size, surrounded by and cut into by rather narrow connective tissue bands. A few of the islands have portal areas at or near their centers.

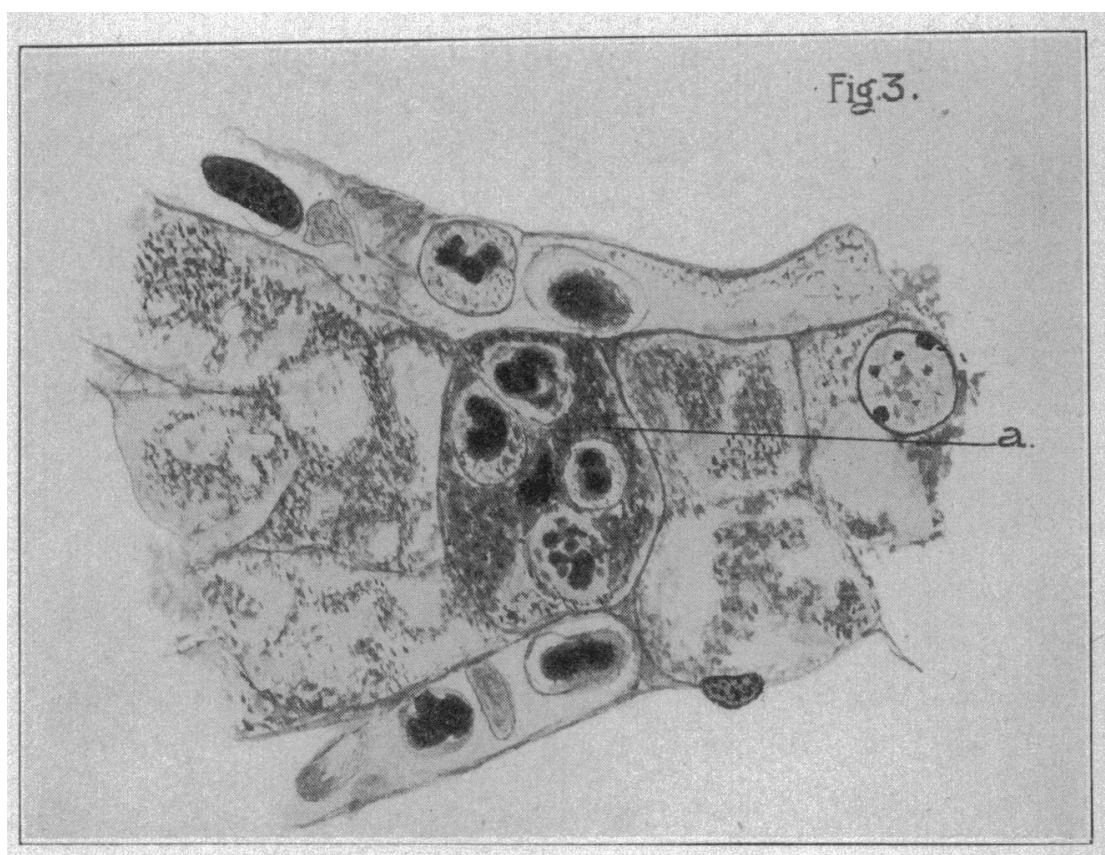

Fig. 3.-High power magnification of the liver from a guinea-pig (No. 46) that had received maximum doses of ethyl alcohol, $a$ is a necrotic liver cell lying between two sinusoids. A few such cells represent the greatest damage that can be effected with alcohol. A few cells lost in this way are replaced perfectly.

Reference to the preceding cases offers a clear explanation of the method of formation of these islands. This case differs from the preceding ones in being a more advanced stage of the sclerotic process. That is, the areas of sclerosis involve all lobules to such an extent that all the central hepatic veins and most of the portal areas are included in the fibrous bands.

The islands of normal liver cells are originally made up of a segment of a lobule or the parts of several lobules that abut on portal tissue. That regeneration has taken place in the original islands is 
shown by the presence of islands larger than any normal lobules. Mitoses of liver cells may be found in many of these cases, but frequently it is difficult microscopically to find evidence of regeneration.

These islands are subject to hyaline degeneration just as the lobules are in the earlier stages of the process. For this reason, and also owing to the inclusion of small focal necroses in persisting parts of lobules, the islands of liver cells are very diffusely cut into by connective tissue bands that are narrower than those surrounding the

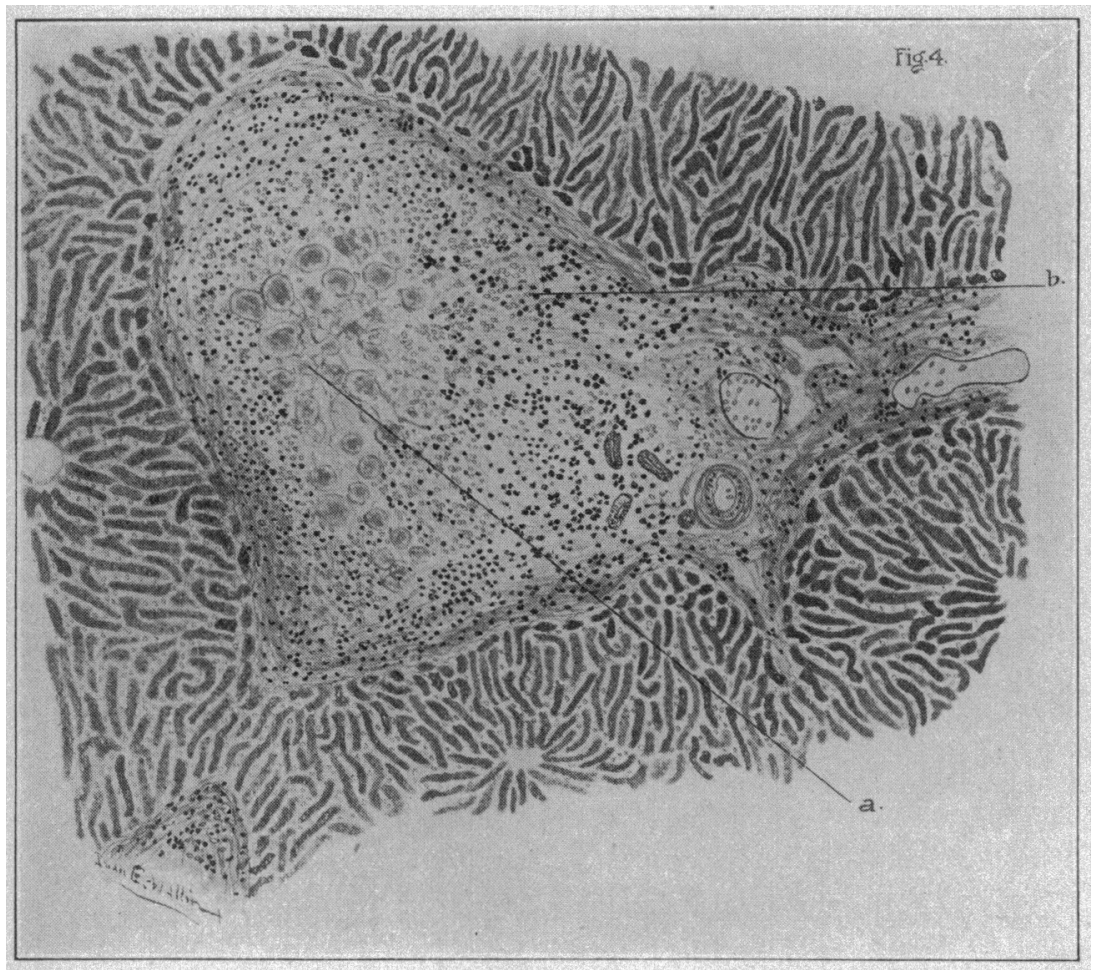

Fig. 4.-Low power magnification of the liver from a rabbit that had never been made the subject of any experiment. This process occurs naturally in rabbits and is found in a large percentage of old animals. The necrosis at $a$ and the leukocytic infiltration at $b$ are followed by a fibrosis such as was met with in Animal 221. This is the change that has been described by those who claim to have produced a cirrhosis in animals by means of ethyl alcohol.

islands. The narrowness of the bands and this irregular cutting up of the islands is often sufficient to differentiate this variety of cirrhosis from the cirrhosis that follows what is known as acute yellow atrophy.

CASE 11.-A. D., woman, aged 46, drank one bottle of beer daily; died thirty days after admission.

Weight of the liver $1,870 \mathrm{gm}$; surface is graular. Microscopically it is like the liver in Case 10. 
CASE 12.-I. C., woman, aged 50. No history; weight of the liver 1,260 gm.; surface is granular. Microscopically it is like that of Case 10 except that many islands are larger.

CASE 13.-R. M., man, aged 47, drank one pint of whisky and three to four beers daily; for three weeks the abdomen had been increasing in size; some jaundice; died ten days after admission.

Weight of the liver, $1,720 \mathrm{gm}$; surface is granular. Microscopically it is like that of Case 10.

CASE 14.-C. D., man, aged 46, drank three to four glasses of whisky per day; for three weeks had been growing weak; admitted to the hospital and died fifteen days later.

Weight of the liver $2,350 \mathrm{gm}$; ; surface is granular. Microscopically the connective tissue bands are narrow and ill-defined, and included in these bands there are a great many cells containing hyalin.

CASE 15.-J. N., man, aged 34, drank much whisky during the previous ten years; had stomach trouble and "dry heaves" for years; delirious for three days before entrance to the hospital, and died ten days later.

Weight of the liver $3,029 \mathrm{gm}$.; surface is granular. Microscopically it is like that in Case 10, except that the islands are larger.

CASE 16.-A. M., man, aged 50, drank seven to eight beers or whiskies daily; quit work three months previous to admission on account of shortness of breath; died twenty-one days after admission to the hospital.

Weight of the liver 1,750 gm.; surface is granular. Microscopically it is like that of Case 10.

CASE 17.-N. H., woman, aged 38, used alcohol for twenty years; in excess for one year; swelling of the abdomen for five weeks; jaundice present; died twelve days after admission.

Weight of the liver $3,180 \mathrm{gm}$.; surface is smooth. Microscopically it is like the liver in Case 10, except that the connective tissue bands are very narrow and the islands very large. The liver cells contain a great amount of fat.

CASE 18.-R. M., woman, aged 32, drank a half pint of gin per week; for six weeks especially sick; when admitted had an alcoholic breath; died thirteen days after admission.

Weight of the liver $1,310 \mathrm{gm}$.; surface is granular. Microscopically it is like that of Case 10.

CASE 19.-E. S., man, aged 37, drank twelve to twenty-five glasses of beer daily and brandy occasionally; for the previous five months he complained of weakness; the previous ten days he was jaundiced and had pain in the epigastrium; died two days after admission.

Weight of the liver 2,900 gm.; surface is granular. Microscopically like the liver in Case 10.

CASE 20.-N. H., woman, aged 38. For the previous nine years the patient used much alcohol; there was jaundice and pain in the back for six months; died one day after admission.

Weight of the liver $2,990 \mathrm{gm}$.; surface is granular. Microscopically like that of Case 10.

CASE 21.-M. O., woman, aged 60. Admitted unconscious following a fall; no history.

Weight of the liver 1,270 gm.; surface is granular. Microscopically like the liver in Case 10.

CASE 22.-W. B., man, aged 50, drank beer, alcohol, and whisky for years; jaundiced for three months; increasing ascites and edema of the legs. 
Weight of the liver $1,555 \mathrm{gm}$; ; surface of the liver is granular. Microscopically like that of Case 10.

CASE 23.-M. F., man, aged 51; alcohol used; admitted in a semiconscious condition with an alcoholic breath; died four days later.

Weight of the liver $1,440 \mathrm{gm}$.; surface is granular. Microscopically like that of Case 10 .

CASE 24.-F. M., man, aged 56, had a "spree" once in two months; vomiting; jaundice; died three days after admission.

Weight of the liver 2,100 $\mathrm{gm}$; ; surface is granular. Microscopically like the liver in Case 10 except that the sclerosis is somewhat less advanced (a few lobules may be found).

CASE 25.-G. M., man, aged 29, had used alcohol steadily and to excess for three to four years; well until three months prior to admission when vomiting and swelling of the abdomen began; died thirty-four days after admission.

Weight of the liver $2,425 \mathrm{gm}$; surface is granular. Microscopically like that of Case 10.

CASE 26.-E. S., man, came into the hospital complaining of acute rheumatism in the right knee; developed delirium tremens and died twelve days after admission; the clinical diagnosis was alcoholism.

Weight of the liver $2,200 \mathrm{gm}$; surface is smooth. Microscopically like the liver in Case 10.

CASE 27.-N. H., woman, aged 41 , drank wine every morning; died six days after admission.

Weight of the liver $2,650 \mathrm{gm}$; surface is granular. Microscopically like that in Case 10.

CASE 28.-C. L., woman, aged 49. Diarrhea, loss of weight, vomiting and enlargement of the abdomen for one month before entrance. Huspand said the patient used alcohol.

Weight of the liver $3,080 \mathrm{gm}$; ; surface is granular. Microscopically like that of Case 10.

CASE 29.-F. P., man, aged 33. Run down for the previous three months; drinking heavily; alcohol in excess for years; since entrance to hospital. delirious.

Weight of the liver $5,335 \mathrm{gm}$; surface is granular. Microscopically like the liver in Case 10, except for cells containing a large amount of fat.

CASE 30.-C. T., woman, aged 53. In bed for two months with vomiting; not asked about alcohol; died thirty-five days after admission to the hospital. After the necropsy the husband stated that the patient drank much brandy.

Weight of the liver $1,380 \mathrm{gm}$.; surface is granular. Microscopically like that of Case 10.

Anatomically, Cases 1 to 9 , inclusive, are not ones of frank cirrhosis. They are included in the series because the cells show a characteristic hyaline degeneration. This hyaline change is present in this variety of cirrhosis of unknown etiology, and is found in no other condition; except, rarely, in an alcoholic (Cases 1 to 9) in which the changes point to the active degenerative stage that ends in a cirrhosis. Whatever the toxic substance active in this cirrhosis, the hyaline change appears to be the degenerative lesion.

Accepting these cases as different stages of the process that ends in this variety of cirrhosis, especial interest attaches to the microscopic: 
changes. In all the earlier cases it is seen that, although the degenerative change strikes quite irregularly throughout the lobule, it makes its first appearance toward the center, and this is the part first lost in the process that extends irregularly and finally destroys the entire normal lobulation.

The descriptions that are available for study deal at length with a fully developed cirrhotic liver, while the degenerative changes that produce this anatomic rearrangement of the liver structure are guessed at by inference. Degeneration and regeneration in the cirrhotic liver are described at length, but little is said in regard to the active lesion that is so severe that the entire normal lobulation is lost. As in other processes that end in sclerosis, the early active stage, summarized in the preceding paragraph and detailed in Cases 1 to 9, inclusive, is the important one to study from the etiologic, anatomic and therapeutic point of view. If the causative factor can be definitely established, it is possible that during this stage the progress of the lesion may be stopped.

The common observation that the livers of those dying from acute and chronic alcoholism show, in the great majority of cases, no change except an abundance of fat in the liver cells, is found true in the study of the necropsies performed at the Boston City Hospital on those dying from alcoholism during fifteen years previous to 1915 . There is no question that alcohol as used by chronic alcoholics produces no liver lesion in the great majority of cases.

Another point that indicates that the use of alcohol acts indirectly or not at all, is the length of time intervening between admission of the patients to the hospital and their death (more than one month in four of the thirty cases). Since an active and extensive degenerative change is present in the liver of a person one month after his last dose of alcohol, the degenerative change either persists for this length of time or the alcohol acts indirectly or not at all on the liver cells. The rapidity of necrosis and solution, and the invasion of affected cells by leukocytes, ending in their rapid removal, makes it very unlikely that seriously injured cells persist in that state for so long a time.

\section{THE ANIMAL LIVER AFTER DOSAGE WITH ALCOHOL}

With a substance so simple chemically as alcohol, one would expect the action on the lower animals to be similar to that in the human, and numerous attempts have been made to clear up the question of so-called alcoholic cirrhosis by administering alcohol to animals. Out of one list of thirty workers who gave ethyl alcohol to animals, seventeen produced no lesion in the liver, while thirteen produced a cirrhosis. Those that produced a cirrhosis worked with rabbits. Rabbits frequently show an increase in round cells in the periportal tissue and 
along the interlobular lines (Fig. 4). In this way islands of liver cells and liver lobules become surrounded by fibroblastic tissue. There seems to be some contention as to whether this process, occurring spontaneously in rabbits, should be called a cirrhosis, but disregarding this technicality, it does correspond to the reproductions and descriptions representing the cirrhosis said to be produced by alcohol in rabbits.

A search through the reports of these investigators is a rather barren one. Those reporting positive results have, as mentioned above, made use of rabbits, and their positive results are based on descriptions that correspond to the natural lesion found in these animals. Although investigators now agree that an extensive necrosis and loss of liver cells leads to the cirrhotic liver as an end result, the majority of the experimental workers have made little or no attempt to demonstrate this active process that leads to the sclerosis. In such a case as this in which all the factors used in the experiments are so accessible, it seems largely a waste of time to go into an extensive critical analysis of the literature.

Since alcohol appeared to be the most obvious factor, it was given persistently to animals until it was found that no lesion, however slight, could be produced. Later, other substances were tried. A total of 300 animals were used in the series of experiments. Of these, 125 were given ethyl alcohol (Table 1).

Alcohol.-The alcohol was given by the stomach, subcutaneously, intraperitoneally, by the rectum, by injection into the common bile duct, and by injection directly into the liver. In the animals receiving the alcohol per os, 80 per cent. alcohol was usually given daily or on alternate days and in doses sufficiently large to render the animal unable to stand. 'Usually it was given on an empty stomach.

In the liver of no animal is there a necrosis and degeneration of liver cells such as is seen in the human cases. Direct injection into the liver and injection into the common duct gave a focal necrosis of course, but the necrotic cells show no peculiarity. In the other animals a few necrotic cells (Fig. 3), usually less than twenty-five per microscopic lobule, are present, but such small numbers of scattered necrotic cells are found in the livers of animals dying from a variety of causes. Animals that died were subjected to necropsy and the organs fixed within one hour, and usually within ten minutes, after death. This is an absolutely necessary precaution, especially in small animals.

The length of time during which the alcohol was given was not great. If it is not possible to produce any degenerative change by the most intensive dosage during as long a period as a month, there is little possibility that alcohol ever produces a lesion in animals that leads to cirrhosis.

Of the remaining 175 animals that received substances other than alcohol, none showed liver lesions similar to those present in human alcohol cirrhosis, except the ones that were given large doses of lead.

Lead.-The liver lesion (Fig. 2) that is produced by lethal or slightly sublethal doses of lead has been described in detail by me. ${ }^{5}$ The hyaline net-

5. McJunkin, F. A.: The Local Action of Lead, Jour. Med. Research, 1915, 32, 271. 
Table Giving Data of Author's Animal Experiments

\begin{tabular}{|c|c|c|c|c|c|c|}
\hline No. & Animal & $\begin{array}{c}\text { Number } \\
\text { of } \\
\text { Doses }\end{array}$ & $\begin{array}{c}\text { Alcohol, } \\
\text { per } \\
\text { Cent. }\end{array}$ & $\begin{array}{c}\text { Amount, } \\
\text { O.c. }\end{array}$ & $\begin{array}{c}\text { Period } \\
\text { Given, } \\
\text { Days }\end{array}$ & Liver ${ }^{1}$ \\
\hline 41-45 & Guinea-pig....... & 39 to 78 & 30 & 5 & 42 to 86 & Negative \\
\hline 46 & Guinea-pig....... & 12 & 60 & 4 & 24 & Occasional necrotic cell \\
\hline 56 & Guinea-pig....... & 15 & 60 & 4 & 30 & Negative \\
\hline 58 & Guinea-pig.... & 24 & 2 & 8 & 45 & Negative \\
\hline 69 & Guinea-pig....... & 20 & 2 & 8 & 43 & Negative \\
\hline 62 & Guinea-pig........ & 8 & 80 & 5 & 17 & Negative \\
\hline 63 & Guinea-pig....... & 8 & 80 & 5 & 23 & Negative \\
\hline 117 & Guinea-pig....... & 29 & 80 & $\mathbf{5}$ & 62 & Negative \\
\hline 118 & Guinea-pig....... & 34 & 80 & 5 & 88 & Negative \\
\hline $\mathbf{1 1 9}$ & Guinea-pig....... & 21 & 80 & 5 & 45 & Negative \\
\hline 120 & Rabbit........... & .. & $95^{3}$ & 0.5 & .. & Focal area of necrosis \\
\hline 124 & Guinea-pig....... & 23 & 80 & 5 & 50 & Negative \\
\hline 125 & Guinea-pig....... & 23 & 80 & 5 & 50 & Negative \\
\hline 126 & Guinea-pig....... & 23 & 80 & 5 & 50 & Negative \\
\hline 127 & Guinea-pig....... & 88 & 80 & 5 & 44 & Occasional necrotic cell \\
\hline 128-138 & Guinea-pig....... & 22 to 80 & 80 & 5 & 24 to 42 & Negative \\
\hline $140-142$ & Guinea-pig.... & 18 to 33 & 80 & 5 & 18 to 33 & Negative \\
\hline 146 & Cat............ & 21 & 80 & 12 & 21 & Negative \\
\hline 148 & Cat............. & 24 & 80 & 12 & 52 & Negative \\
\hline 149 & Cat.......... & 15 & 80 & 12 & 34 & Few necrotic cells \\
\hline 150 & Cat.......... & 11 & 80 & 12 & 23 & Negative \\
\hline 152 & Cat............. & 6 & 80 & 12 & 15 & Negative \\
\hline 153 & Cat............. & 7 & 80 & 12 & 22 & Negative \\
\hline 154-158 & Cat............. & 5 to 12 & 95 & 8 & 10 to 62 & Negative \\
\hline $169-17 \overline{5}$ & Rabbit........... & 3 to 10 & 80 & 6 & 6 to 11 & Negative \\
\hline 187 & Cat............. & .. & $80^{4}$ & 1 & .. & Focal necrosis \\
\hline 199 & Guinea-pig....... & .. & $40^{5}$ & 5 & .. & Negative \\
\hline 200 & Guinea-pig....... & .. & $20^{\circ}$ & 1 & .. & Negative \\
\hline 201 & Guinea-pig........ & 2 & $40^{7}$ & .. & 2 & Negative \\
\hline 202 & Guinea-pig....... & 2 & $40^{7}$ & .. & 2 & Negative \\
\hline 206 & Guinea-pig....... & 3 & 40 & 5 & 3 & Negative \\
\hline 208 & Guinea-pig....... & 31 & 40 & 5 & 38 & Occasional necrotic cell \\
\hline 210 & Guinea-pig....... & 1 & 40 & 5 & 1 & Negative \\
\hline
\end{tabular}

1. The condition of liver is not recorded in a few cases not flxed within ten minutes after death. Immediate fxation is of the utmost importance.

2. Port wine.

3. Directly into liver. The alcohol was always given per os on a fasting stomach except when otherwise specifed

4. Injected into hepatic duct; animal killed in three days.

5. Injected into mesenteric vein; animal died immediately.

6. Injected into mesenteric vein; animal died in forty-efght hours.

7. Injected into rectum. 
Table Giving Data of Author's Animal Experiments-(Continued)

\begin{tabular}{|c|c|c|c|c|c|c|}
\hline No. & Animal & $\begin{array}{l}\text { Number } \\
\text { of } \\
\text { Doses }\end{array}$ & $\begin{array}{l}\text { Alcohol, } \\
\text { per } \\
\text { Cent. }\end{array}$ & $\begin{array}{c}\text { Amount, } \\
\text { O.c. }\end{array}$ & $\begin{array}{l}\text { Period } \\
\text { Given, } \\
\text { Days }\end{array}$ & Liver ${ }^{1}$ \\
\hline 211 & Guinea-pig....... & $\mathbf{1}$ & 40 & 5 & 2 & Negative \\
\hline 214 & Rabbit.......... & 10 & $40^{8}$ & 7 & 10 & Negative \\
\hline 215 & Guines-pig....... & 2 & $40^{8}$ & 6 & 3 & Negative \\
\hline 216 & Guinea-pig....... & 2 & $40^{8}$ & 4 & 2 & Negative \\
\hline 217 & Rabbit........ & 1 & 40 & 15 & 2 & Negative \\
\hline 218 & Dog............. & 29 & 40 & 60 & 61 & Negative \\
\hline 219 & Rabbit...... & 3 & 40 & 15 & 4 & Negative \\
\hline 220 & Guinea-pig.. & 8 & 40 & 3 & 9 & Negative \\
\hline 221 & Rabbit...... & 2 & 40 & 20 & 2 & $\begin{array}{l}\text { Surface of liver rough; } \\
\text { mileroscopically marked } \\
\text { sclerosis; negative }\end{array}$ \\
\hline 222 & Rabbit.......... & 3 & 40 & 20 & 4 & $\begin{array}{l}\text { Negative } \\
\text { Neristive }\end{array}$ \\
\hline 223.227 & Guinea-pig... & 10 to 64 & $20^{8}$ & 4 & 23 to 72 & Negative \\
\hline $228-231$ & Rat............. & 3 & $20^{s}$ & 8 & 3 & Negative \\
\hline 243 & Guinea-piga ${ }^{9} \ldots \ldots$ & . & . & $\cdots$ & .. & $\begin{array}{l}\text { Necrotic foci involving } \\
\text { several lobules }\end{array}$ \\
\hline 244 & Guinea-pig $9 . .$. & $\cdots$ & .. & -. & .. & Necrotic foci involving \\
\hline 246 & Guinea-pig ${ }^{9} .$. & .. & .. & .. & . & $\begin{array}{l}\text { several lobules } \\
\text { Necrotic foci involving } \\
\text { several lobules }\end{array}$ \\
\hline 247 & Guinea-pig ${ }^{a} .$. & .. & .. & $\cdots$ & .. & Necrotic foci involving \\
\hline 250 & Guinea-pig ${ }^{\theta}$. & .. & .. & . & .. & Necrotic foci involving \\
\hline $252-263$ & Guinea-pig ${ }^{9} \ldots \ldots$ & .. & $\cdots$ & .. & .. & Necrotic foci involving \\
\hline 270 & Rabbit....... & 8 & $80^{10}$ & 14 & 14 & $\begin{array}{l}\text { several lopules } \\
\text { Negative }\end{array}$ \\
\hline $272-278$ & Guinea-pig... & 8 & 8010 & 14 & 1 to 16 & Negative \\
\hline 279 & Guinea-pig... & 3 & $80^{11}$ & 4 & 6 & \\
\hline 280 & Guinea-pig..... & 2 & $80^{11}$ & 4 & 6 & Central necrosis \\
\hline 281 & Guinea-pig....... & 2 & $80^{11}$ & 4 & 6 & \\
\hline 282 & Guinea-pig....... & 2 & $80^{11}$ & 4 & 6 & Central necrosis \\
\hline 283 & Guinea-pig....... & 9 & $80^{11}$ & 4 & 30 & Slight central necrosis \\
\hline 284 & Guinea-pig....... & 18 & $80^{11}$ & 4 & 54 & Negative \\
\hline 285 & Guinea-pig....... & 27 & $80: 1$ & 4 & 60 & No necrosis \\
\hline 286 & Guinea-pig....... & 33 & $80^{11}$ & 4 & 69 & Negative \\
\hline 287 & Guinea-pig....... & 40 & $80^{11}$ & 4 & 80 & Negative \\
\hline 288 & Gulnea-pig....... & 36 & $80^{11}$ & 4 & 80 & Marked central necrosis \\
\hline 289 & Guinea-pig... & 23 & $80^{11}$ & 4 & 92 & Negative \\
\hline 290 & Guinea-pig....... & 23 & $80^{11}$ & 4 & 92 & \\
\hline 291 & Guinea-pig....... & 24 & $80^{11}$ & 4 & 59 & Negative \\
\hline
\end{tabular}

1. The condition of liver is not recorded in a few cases not flxed within ten minutes after death. Immediate flxation is of the utmost importance.

8. Infected subcutaneously.
9. Injected 0.25 c.c. 80 per cent. alcohol into common duct after ligation of cystic fium.

10. After chloroform anesthesla lasting two hours.

11. Alcohol containing 1 per cent. chloroform. 
Table Giving Data of Author's Animal Experiments-(Continued)

\begin{tabular}{|c|c|c|c|c|c|c|}
\hline No. & Animal & $\begin{array}{c}\text { Number } \\
\text { of } \\
\text { Doses }\end{array}$ & $\begin{array}{c}\text { Aleohol, } \\
\text { per } \\
\text { Cent. }\end{array}$ & $\underset{\text { C.c. }}{\text { Amount, }}$ & $\begin{array}{c}\text { Perlod } \\
\text { Given, } \\
\text { Days }\end{array}$ & Liver $^{1}$ \\
\hline 292 & Guinea-pig....... & 34 & $80^{12}$ & 4 & 69 & Central necrosis \\
\hline 293 & Gưinea-pig....... & 34 & $80^{12}$ & 4 & 69 & Central necrosis \\
\hline 294 & Guinea-pig....... & 34 & $80^{12}$ & 4 & 69 & Slight central necrosis \\
\hline 295 & Guinea-pig....... & 35 & $80^{12}$ & 4 & 80 & \\
\hline 296 & Guinea-pig....... & 35 & $80^{12}$ & 4 & 80 & . \\
\hline 297 & Dog........ & 24 & $80^{13}$ & 7 & 77 & Marked central necrosis \\
\hline 298 & Dog...... & 25 & $80^{13}$ & 7 & 76 & Central necrosis \\
\hline 299 & $\operatorname{Dog} \ldots \ldots \ldots$ & 14 & $80^{13}$ & 7 & 65 & Central necrosis \\
\hline 300 & Dog............ & 60 & $80^{13}$ & 7 & 60 & Slight central necrosis \\
\hline
\end{tabular}

12. With 3 per cent. chloroform.

13. With 4 per cent: chloroform.

work present in the liver cells of animals receiving lead salts blackens when treated with an alkaline sulphid. The hyalin-containing cells from cases of human cirrhosis do not give this reaction. Altogether, seventy-six animals were given lead salts and their livers examined microscopically.

Chloroform.-Fifteen animals were given chloroform in doses of sufficient size to produce slight to extensive central necrosis. These animals were used to control animals that received both alcohol and chloroform.

Pancreatin.-Twenty-nine animals received varying strengths and forms of pancreatin per os and by injection into the bile passages. The liver was negative so far as changes suggesting those present in human cirrhosis are concerned.

Bacterial Toxins.-Sixteen animals were given by the mouth the cultural products of a number of intestinal bacteria alone and in combination with alcohol. Liver negative.

Acetaldehyd.-Eight animals. Liver negative so far as changes like those present in human cirrhosis are concerned.

Formaldehyd.--Seven animals; liver negative.

Other Substances.-Pepsin, hydrochloric acid, chloral hydrate, acetone, acetic acid, sodium acetate, stannous chlorid, copper sulphate, mercuric chlorid, bismuth and Rochelle salts. Twenty-four animals; liver negative.

\section{SUMMARY AND CONCLUSIONS}

After the elimination of cases of cirrhosis of known etiology of the mechanical, infectious and syphilitic varieties, many cases fall into a class of unknown etiology. These cases appear to be of toxic origin, but differ from the central scleroses produced by known bacterial toxins and by chloroform, as well as from the cirrhosis that may follow acute yellow atrophy. Alcohol is suggested as the causative agent by the history of these cases, but there is no further evidence to indicate that it injures the liver. On the other hand, the frequentlymentioned fact that the percentage of cirrhosis among those dying 
from chronic alcoholism is only slightly greater than it is among those dying from all other causes, indicates that this substance has no direct action on the liver.

A point brought out in the histologic study of a series of human cases is that there is a very active and characteristic degeneration and necrosis of liver cells present even as long as a month after the patient received his last alcohol.

A further reason for thinking that alcohol does not act directly on the liver to produce a cirrhosis is that it does not injure the liver in the lower animals. It not only does not produce a cirrhosis, but it produces no noteworthy lesion whatsoever of the liver cells.

If alcohol works no damage on the liver, or does so only indirectly, the question of the number of factors at work in the production of these cases of cirrhosis of unknown etiology arises along with the problem of the nature of the hepatic poison. In regard to the first of these questions, the uniformity of the cellular changes, especially the characteristic hyaline degeneration of the hepatic cells, and the very irregular cutting up of the lobules and islands by rather narrow sclerotic bands, point to a single causative agent or to poisons acting alike.

As to the nature of the poison, there is little evidence now at hand. Of a number of substances given to animals, lead is the only one that produces a hyaline change. The failure of the hyalin of human liver to react with an alkaline sulphid, as does that produced by lead in experimental animals, indicates that lead is not the active agent in this variety of cirrhosis. The uniformity of the lesion of these cases brought out in this study at least tends to show that there is here a variety of cirrhosis, the etiology of which is for future solution. The so-called alcoholic cirrhosis is not produced directly by ethyl alcohol, that is, the liver is not injured by the alcohol carried to it through the blood or lymph.

Fourth Street and Reservoir Avenue. 